\title{
EXPLORING THE NEXUS BETWEEN TOURISM DEMAND AND CULTURAL SIMILARITY
}

\author{
YUN HSING (YH) CHEUNG* AND SHRABANI SAHA $\dagger$ \\ *School of Business, Faculty of Business and Law, Edith Cowan University, Joondalup, WA, Australia \\ $\dagger$ Lincoln Business School, University of Lincoln, Brayford Pool, Lincoln, UK
}

\begin{abstract}
This article attempts to bring an economic underpinning to tourism research. It uses the gravity model to derive an econometric model to explore the relationship between cultural similarity and tourism demand, with special reference to Australia inbound tourism from 42 source countries. Since language and religion are thought to be the main exposition and carrier of culture, we developed a continuous, normalized, and time variant index to capture the similarity in language and religious profile between a source country and Australia. The inclusion of these indexes in an empirical model yields OLS and quantile results that support the belief that there is a close link between culture similarity and tourism demand.
\end{abstract}

Key words: Culture; Tourism; Language similarity index; Religion similarity index; Australia inbound tourism

\section{Introduction}

The statistics provided by the World Tourism Organization showed that international tourist arrivals worldwide increased by almost $40 \%$ from 674 to 940 million in the first decade of this century. With the advance of affordable intercontinental transport, traveling is no longer the pastime and exclusivity of the privilege few. Consequently, tourism has become a major industry to many countries, developed and developing alike. Research in tourism has also grown in pace with the surge in tourism numbers.
The role of culture has been considered in many areas of economic research (trust, economic development, corruption, international trade, and regional economics, to name a few) and in other business disciplines. There are two strands of tourism research concerning the role of culture. The first strand examines culture as a determinant in tourism demand. Tourism products offered by various destination countries, with different cultures, are no longer heterogeneous in the eyes of the tourists. Crouch and Ritchie (1999) considered ethnic ties as a "core resource and attractor" of a destination. Zhang and Jensen (2007) suggested tourists may choose to visit 
a country because of cultural affinity. These imply countries with similar culture may engage more in tourism. Consequently, more and more empirical research in recent years (e.g., Crotts, 2004; Ng, Lee, \& Soutar, 2006; Seetanah, Durbarry, \& Ragodoo, 2010; Vietze, 2012) have incorporated some form of cultural factor into their models.

Parallel to the above, the study of cultural tourism has also emerged (e.g., Boukas, Ziakas, \& Boutstras, 2013; Galí-Espelt, 2012; McKercher \& du Cros, 2003; Richards, 1996). Tourists are cultural tourists if they travel for their cultural needs, and the tourism they carry out is cultural tourism. Cultural tourism is traditionally associated with visiting historical, religious, and archaeological sites, and museums, but it has been extended to include iconic places, film and music festivals, and large-scale sport events. Donaire (2008, cited in Galí-Espelt, 2012) pointed out that cultural tourism involved not only cultural objects but also objects that were looked at in a "cultural way." Note that cultural tourism does not entail cultural similarity between the source and the destination country. So this group of research should not be mixed up with the research in the first strand.

This article focuses on the effect of cultural similarities on tourism. We posit that a better understanding of the cultural effect on tourism will be beneficial to tourism operators and governments alike in getting a bigger piece of the world tourism pie. It contributes to current tourism literature in three ways. First, it provides a review of the various methods of measuring cultural similarities or differences in empirical studies. Second, based on sound economic principle, it introduces a new continuous, normalized, and time variant index to measure cultural similarity in terms of language and religion. Third, it explores the nexus between cultural similarity and tourism demand. To put concepts into context, this article is interested particularly in examining whether cultural similarities are imperative in bringing tourists into a multicultural society like Australia.

We organize the remainder of this article as follows. The next section examines briefly the various ways to measure cultural differences among countries, followed by a review of the current practice of integrating cultural similarities or differences in empirical studies. Then, we examine the legitimacy of using gravity model as a model for studying tourism demand and deriving the basic theoretical model for our empirical study, followed by the construction of the language and religion similarity indexes that are applied in this study. It also reviews the literature in developing such indexes. In the subsequent section, we introduce the econometric model used in the cross-sectional study of Australian inbound tourism for the year 2010, followed by a section devoted to the discussion of the regression results from OLS and quantile estimates. The last section summaries the empirical findings and discusses their policy implications for tourism operators and government officials.

\section{Measuring the Effect of Culture Through Cultural Differences}

Despite the frequent use of the word culture in daily conversation, it hardly means the same to any two speakers. The nonuniformity of its definitions is well reflected not only in the dictionary but also in academic research. The New Penguin Dictionary put forward two definitions. The first one is "the customary beliefs, social norms, etc. of a racial, religious, or social group." The second one is "the socially transmitted pattern of human behaviour that includes thought, speech, action, institutions, and artefacts." Hofstede (1980) defined culture as "the interactive aggregate of common characteristics that influence a human group's response to its environment" (pp. 25-26). In a survey of how culture affects economic outcome, Guiso, Sapienza, and Zingales (2006) defined culture as "those customary beliefs and values that ethnic, religious, and social groups transmit fairly unchanged from generation to generation" (p. 23).

The nonuniformity arises from the fact that the notion of culture is a construct that is difficult to define precisely and comprehensively. The lack of a clear-cut definition only adds to the difficulty of quantifying culture and examining its effect. Nevertheless, there are numerous attempts to operationalize the concept of culture using comparative studies. A country is set as a benchmark and compared with other countries. Their dissimilarities are quantified in terms of cultural distance.

As far as we know, Beckerman (1956) was the first empirical work to suggest that psychic distance 
arising from cultural differences might act as a barrier of trade. Yet he did not incorporate cultural differences in his study nor did he suggest how it could be measured. The impact of psychic distance was not mentioned again until the investigation of the internationalization processes of Swedish firms in the 1970s. Johanson and Vahlne (1977) suggested that it was more successful and less risky for Swedish firms to expand into psychically close countries, in terms of language, culture, political system, education, and level of industrial development. Differences in these factors would impede the flow of information between countries and their accurate interpretation. Subsequent researchers used one or more of these differences to proxy cultural differences.

The first attempt to measure cultural differences systematically was carried out in a study of cross-cultural differences in work values. Hofstede (1980) measured the culture differences across IBM subsidiaries in 64 countries using four cultural scores: individualism, masculinity, power distance, and uncertainty avoidance. ${ }^{1}$ His four-dimensional schema was influential and was employed extensively in the area of international business and marketing. Yet, the relevance of original 1980 and updated scores in 2001 has been gradually eroding over time.

Ludwig Wittgenstein once said, "The limits of my language mean the limits of my world." Language is found to affect how we think and perceive things, which in term shapes our experiences. Languages that have a two-gender system may affect how the nature of an object is perceived. The word bridge is seen as more masculine in Spanish than in German. To complicate things, the same word may have different connotations. The word dog is largely associated with being helpful and loyal among English speakers. But for Chinese speakers, the same word has a dishonorable and unsavory implication such as traitor or abettor. The power of language even determines our economic welfare. Chen (2013) suggested that tenseless languages, compare to a language using tense to grammatically differentiate the time of action, tend to foster future-oriented behavior, and therefore a higher national saving rate.

Not only language affects how we perceive things, it has a more prominent role in shaping culture that is recognized by anthropologists and economists alike. Cavalli-Sforza, Menozzi, and Piazza (1994) suggested, "Language is a major expression and determinant, as well as a vehicle of culture" (p. 294). Lazear (1999) and Akerlof and Kranton (2000) suggested that language is a good proxy of culture. If that is the case, then linguistic distance between any two languages becomes a handy way of measuring cultural differences. Following this vein, various linguistic distance indexes are developed to proxy for cultural differences. The differences in pronunciation of words having the same meaning give us the Levenshtein distance (Isphording \& Otten, 2013). The ancestral distance of words having the same meaning gives us the Lexicostatistical distance (Dyen et al., 1992, as cited in Ginsburgh, 2005). The taxonomic relationships between languages give us the Taxonomic distance (Eff, 2004, 2008). Irrespective of which linguistic distance is used, it is often incomprehensible to researchers other than linguists. To add to their woe, they are time invariant, reducing their desirability in empirical models.

\section{Incorporating Cultural Differences in Empirical Models}

Cultural effects can be incorporated within or without a theoretical framework. The popular way of incorporating cultural effects within a theoretical framework in economics is through the gravity model, which is efficient in describing the attraction of the likes. Based on Newton's law of gravitation force, the gravity model (e.g., Anderson, 1979; Bergstrand, 1985) estimates the international or intranational flows of information, products and services, and people. A vector of variables is added to the denominator of the gravity model to measure hindrance factors of trade such as transaction costs arising from differences in language, religion, and legal systems. This method allows the "physical distance" between two countries to be "lengthened" or "shortened" by cultural distances. Examples of this approach are abound (Bergstrand, 1985; Felbermayr \& Toubal, 2010; Guo, 2007; Hutchinson, 2005; Karemera, Oguledo, \& Davies, 2000; Rauch \& Trindade, 2002).

Cultural effects are incorporated without a theoretical framework by using dummy variables. Countries with similar culture are grouped into mutually 
exclusive and exhaustive categories in empirical studies (e.g., Crotts, 2004; Ng et al., 2006; Seetanah et al., 2010; Vietze, 2012). Despite the simple treatment of dummy variables (no theoretical underpinning, the ordinal nature of the variables, and time invariance), empirical studies using dummy variables showed that cultural similarity did have a positive effect on tourism demand. This result is not surprising. There is research in brain study and psychology showing that people feel more relax when they are in contact with something that is familiar and they feel anxious (or aroused) when they are in contact with something that they are not familiar with. In tourism, this may play a part in the direction of traffic. People would feel more at ease when visiting a country where the people speak the same language or believe in the same religion. That is, similarities between the languages and religions of the source and destination countries may be conducive to tourism. Of course, we cannot rule out that some traveling is to seek thrills and to experience the exotic. In such instances, cultural similarity would have some negative influence on the destination decision and cultural difference is synonymous with tourist attraction.

\section{Gravity Model}

In this study, we want to study tourism demand, with specific reference to Australia, using the gravity model. If tourism could be seen as exchange of tourists, then the inbound tourism to Australia (or any other destination country) can be adequately captured by a modified gravity model. More specifically, a vector $X$ incorporating variables peculiar to tourism is inserted into the denominator of the model

$$
N_{i j}=K M_{i}^{\alpha_{i}} M_{j}^{\alpha_{j}} X_{i j}^{-\beta} d_{i j}^{-\gamma}
$$

where $N_{i j}$ is the number inbound tourists from source country $i$ to destination country $j, M$ is population, $d$ is the distance between the two countries, $K$ can now be interpreted as a constant of proportionality which can be interpreted as $\left(1 / \sum M\right)$, and the parameters $\alpha \beta, \gamma>0$.

Henderson and Millimet (2008) showed that this type of equation could be estimated either in levels (first-order linearity) or in natural logs (second-order log-linearity). The log approach has the advantage that nonnormal variables could become normalized through the transformation. In view of that, the second approach is preferred.

$$
\ln N_{i j}=\ln K+\alpha_{i} \ln M_{i}+\alpha_{j} \ln M_{j}-\beta \ln X_{i j}-\gamma \ln d_{i j}
$$

Since the population of the destination country $M_{j}$ is constant for a particular time irrespective of the sampled source countries, it can be net out and forms part of the new constant term $K^{*}=\left(\ln K+\alpha_{j}\right.$ $\ln M_{j}$ ). Therefore, we have the following $\log$-linear model:

$$
\ln N_{i j}=K^{*}+\alpha_{i} \ln M_{i}-\beta \ln X_{i j}-\gamma \ln d_{i j}
$$

The variables in vector $X$ that are relevant to tourism study are thought to be language, religion, income, price of tourism of alternative destination country, ability of the destination country to provide tourism services, and exchange rate of the source country.

The inclusion of an alternative destination country for each source country is to highlight the existence of what is known as "multilateral resistance" (see Anderson \& van Wincoop, 2003), which is crucial in a gravity model for consistent estimation. ${ }^{2}$

The log-linear model, presented in equation (1), not only derived from a well-accepted economic model, it has three added advantages when it comes to estimation. It can generate variable marginal effects and constant elasticities. It imposes nonnegative restrictions on variables and it allows the random errors in the equations to be normally distributed (Lim, 2006).

\section{Language and Religion Similarity Indexes}

Inspired by Eff (2004, 2008), we develop a cultural similarity index using a method that is underpinned by economic theory. Instead of emphasizing the difference between countries, we produce an index to measure their similarities. People of similar backgrounds and cultures seem to mix much more easily and that affects their choices. ${ }^{3}$

We ask ourselves the question: What is the best index of cultural similarity? The answer will depend on the use of the index. A cultural similarity index should be evaluated against some general criteria: (a) easy to understand and to calculate, 
(b) continuous and normalized, (c) based on secondary data that are readily available, (d) varied with time to cope with rapid changes in social and economic environment, and (e) able to withstand the test of ecological fallacy.

The last criterion needs to be emphasized. A failure to account for ecological fallacy would be a major flaw in the age of mass migration and the advocacy of multiculturalism. It is inappropriate to assume that language, religion, and other social measures are homogeneous across a modern nation. This is especially more relevant than the cultural distance in the era of multiculturalism where a national identity is more difficult to define. Nowadays, it is not difficult to find that multiple languages are spoken and multiple religions are practiced within a country. The index has to be able to account for variation of languages and religions within a country. That is, countries should be compared with respect to their language and religion (and other possible measures) profiles.

Our formulation is based on the principle of Berry's index measuring the degree of horizontal diversification in industrial economics. ${ }^{4}$ The language dissimilarity between country $i$ and $j\left(D_{i j}\right)$ is defined as

$$
D_{i j}=1-\sum_{k=1}^{K} l_{i k} l_{j k} \quad \text { with } 0 \leq D_{i j} \leq 1
$$

where $l_{i k}$ is the percentage of population (expressed in decimals) in country $i$ speaking language $k$ and $l_{j k}$ is the percentage of population in country $j$ speaking language $k$. There are $K$ languages accounted for. This index is a continuous variable ranging from 0 to 1 with $D_{i j}=0$, indicating the language profiles of the two countries are the same, and $D_{i j}=$ 1 , indicating $100 \%$ different.

Since we are interested in similarity rather than dissimilarity of languages spoken in two countries, we can extract $\sum l_{i k} l_{j k}$ to form the language similarity index $\left(L_{i j}\right)$, i.e.,

$$
L_{i j}=\sum_{k=1}^{K} l_{i k} l_{j k} \quad \text { with } 0 \leq L_{i j} \leq 1 \text { and } 0 \leq L_{i i} \leq \frac{1}{K}
$$

The language similarity index measures the probability that two persons randomly selected from the two countries speak the same language. The value $L_{i j}=0$ indicates complete dissimilarity and $L_{i j}=1$ indicates both countries speaking one and only one common language. The index is also valuable for study of language similarity within the same country, as $L_{i i}$ measures the probability that two persons randomly selected within a multicultural society who speak the same language. ${ }^{5}$ This approach is flexible because it can be seen from two viewpoints: cultural similarity or cultural differences. Researchers can adopt either viewpoint depending on their research focuses.

Similar to the Berry's index, the value of the index is affected by two factors: the number of languages spoken and the similarity of the two language profiles. By language profile we mean the percentage of people speaking each language. For example, if there are three languages-English, Spanish, and French-spoken in both countries, then the profiles are identical only if the three percentages are identical. In reality, one can imagine that the number of languages spoken in any two countries and the percentage of people speaking each language would differ. Suppose Country A has the following language profile (English, 40\%, French 40\%, Spanish 20\%), and Country B has a slightly different language profile (English 30\%, French 30\%, Spanish 40\%). Then $L_{A B}=0.32$, which means that there is only a $32 \%$ chance that two person randomly drawn from the two populations will speak the same language.

This method of computing language similarity can account for ecological fallacy. It takes into account of all the languages spoken within both countries. The weakness, like all other measures, is its failure to account for secondary language. This would underestimate (overestimate) the language similarity (dissimilarity) between countries. The language similarity index also improves on simple measures such as dummy variables in providing a continuous variable. It is also superior to the Hofstede's $(1980,2001)$ five-dimensional cultural measure and its variants because the language similarity index varies over time and with respect to country pairs.

Since religion is recognized as part of culture, we adopt the same methodology to measure the similarity of religious profiles between countries. Religious similarity index $R_{i j}$ between two countries $i$ and $j$ is calculated as follows

$$
R_{i j}=\sum_{k=1}^{K} r_{i k} r_{j k} \quad \text { with } 0 \leq R_{i j} \leq 1 \text { and } 0 \leq R_{i i} \leq \frac{1}{K} .
$$


We have to point out that no person would practice two religions, so this index does not have the innate weakness of language similarity index of not taking into account secondary language.

The language similarity index between any sampled source country and Australia is constructed based on equation (3). There were hundreds of languages spoken in Australian homes at the time of 2006 census. To simplify our calculation only 37 languages are taken into consideration. ${ }^{6}$ Likewise, the religious similarity index is constructed based on only seven religions: Protestant, Roman Catholics, Eastern Orthodox, Islam, Buddhism, Indigenous, and others (including atheists). Changes in the language similarity index and religious similarity index are certainly very slow. Therefore, we expect the two indexes would be quite stable over time, at least in the near term. The information about religions and languages for Australia was obtained from the 2006 census (Australian Bureau of Statistics, 2007). As for the 42 sampled source countries, their information was obtained from the Central Intelligence Agency (2012) supplemented by data from the European Commission (2012). The values of the two indexes are shown in the Appendix. ${ }^{7}$

If there is an objection of having two cultural indexes in the same model, then a composite cultural index can be calculated by multiplying the two indexes together (see Saha, Grounder, \& Su, 2009; Shen \& Williamson, 2005).

\section{Econometric Models}

This section puts forward the econometric models that examine the role of cultural similarity in attracting inbound tourists to Australia. Based on equation (1), the relationship between inbound tourism and the cultural similarity is structured as follows:

$$
\begin{aligned}
\ln N_{i} & =\beta_{0}+\beta_{1} R_{i}+\beta_{2} L_{i}+\beta_{3} d_{i}+\beta_{4} \ln Y_{i}+\beta_{5} \ln E_{i} \\
& +\beta_{6} \ln P_{i}+\beta_{7} \ln W_{i}+u_{i}
\end{aligned}
$$

where $N$ is inbound tourist number to Australia from source country $i, R$ is the religious similarity index between source country $i$ and Australia, $L$ is the language similarity index between source country $i$ and Australia, $d$ is distance between source country $i$ and Australia, $Y$ is income (measured by per capita real GDP) of source country $i, E$ is real exchange rates defined as the price of US dollar in terms of currency $i, P$ is the population of source country $i$, and $W$ is the tourism price (proxy by labor cost) in the alternative destination country of source country $i$. Note that the population of Australia, being a constant in a cross-sectional study, is integrated into the regression constant [see the definition of $K^{*}$ in equation (1)].

The dependent variable of this study is inbound tourist numbers into Australia from 42 source countries collected from the Australian Bureau of Statistics. ${ }^{8}$ The language and religion coefficients are the main interest of this study. The hypothesis of our econometric model is that cultural similarity can affect a country's tourism demand positively. That is, the expected sign of both $\beta_{1}$ and $\beta_{2}$ are positive, which implies an increase in language or religious similarity between source country $i$ and Australia brings more tourists from that country to Australia.

The other independent variable of interest is the population of the source country, a variable from the gravity model. Population plays an important role as highly populated countries are likely to generate large number of outbound tourists. The sign of the population coefficient is expected to be positive because the larger the population of a source country the larger the tourists number it can provide.

Income, real exchange rate, and distance are regular control variables in tourism models. Therefore, they are also included in our tourism demand modeling process. According to the literature, income and real exchange rate variables are found to be important leading economic indicators for the demand for international tourism (Lim, 2006; Saha \& Yap, 2014). Real per capita GDP is used as a proxy for income and it is calculated based on the purchasing power parity (PPP) converted GDP per capita in a country relative to the US (Lim, 2006). Real per capita GDP represents the affordability of the tourists to visit other countries. Therefore, it is expected that a rise in income increases demand for tourism.

The real exchange rate variable measures the national currency price of Australian dollar adjusted by PPP over GDP. With only cross-sectional data in our study, the real exchange rates between the Australian dollar and the US dollar are invariant; 
therefore, we take the national currency price of US dollar adjusted by PPP over GDP, which is readily available from Penn World Table (https://pwt.sas. upenn.edu/php_site/pwt_index.php), as a proxy. The real exchange rate, according to Lim (2006), reflects the relative tourism prices between source and destination countries. When a source country's currency depreciates with respect to the US dollar, the travel cost from the source country will be more expensive, thus discouraging outbound tourism. Therefore, a negative sign is expected for the real exchange rate coefficient. The data for population, real per capita GDP, and real exchange rates are obtained from Penn World Table.

As for the distance between source countries and Australia, it is usually measured by the air distance or travel time between the two capital cities. This rule is reasonable for smaller countries that falls into the same time zone. With the Australian continent spanning three time zones, the distances between the various source countries and Australia are calculated using three entry ports. ${ }^{9}$ European countries, countries from subcontinent, and from Southeast Asia enter Australia via Perth. Countries from North and Northeast Asia and Americas enter via Sydney, and tourists from Pacific islands come in through Brisbane. The data for the distances are also presented in the Appendix.

The tourism prices of alternative destination countries are included to measure the competition Australia faces and also to ensure consistent estimation. This variable can also act as a proxy of income of the alternative destination and its ability to produce tourism services, and it provides a comparative measure between alternative destinations and Australia. From a competition viewpoint, an increase (decrease) in the tourism price of an competitor is expected to advantage (disadvantage) Australia as tourists from the relevant source country find Australia a relative cheaper (expensive) place to visit. In this study, labor cost acts as a proxy for tourism price. With the inclusion of real exchange rate as a separate explanatory variable, labor cost is expressed in US dollars.

For simplicity sake, the alternative destination country for each source country is assumed to be its top destination country. If Australia happens to be its top destination country, then the second highest ranked country is selected to be the alternative destination. The list of alternative destinations is obtained from Euromonitor International and is presented in the Appendix.

We examine the effect of cultural similarity on Australian inbound tourist arrivals in a cross-country framework for 42 source countries for the year 2010 using OLS. Because a cross-sectional model is notorious for having heteroscedasticity and social data are often not normally distributed, regressions at the 25th, 50th, and 75th quantiles are performed for quality assurance purpose. The results from these quantile regressions also give us a more comprehensive understanding of the cultural effect on Australian inbound tourism from various sizes of source countries. The conditional quantile of $\ln N_{i}$ is

$$
\begin{aligned}
\ln N_{i}= & \beta_{0 \theta}+\beta_{1 \theta} R_{i}+\beta_{2 \theta} L_{i}+\beta_{3 \theta} d_{i}+\beta_{4 \theta} \ln Y_{i} \\
& +\beta_{5 \theta} \ln E_{i}+\beta_{6 \theta} \ln P_{i}+\beta_{7 \theta} \ln W_{i}+u_{i \theta}
\end{aligned}
$$

where $\theta$ denotes the quantile applied.

\section{Empirical Results}

This section discusses our empirical results. The first part of the analysis focuses on the OLS regression results while the second part the quantile regression results.

\section{OLS Estimation Results}

Table 1 reports the OLS regression results from EView7 using equation (5) for 42 sampled countries for the year 2010. Column 2 reports the baseline model, presented by equation (5). Column 3 presents specification 2 with only language variable. Column 4 presents specification 3 with only religion variable. Column 5 presents specification 4 with a language and religion interactive variable. Column 6 presents specification 5 , which is the same as specification 4 except income is set as a lagged variable to capture the fact that if any increase in income stimulates travelling in the next period.

The regression coefficient for language in both the baseline model and specification 2 is positive and significant at $1 \%$ level, indicating the higher the language similarity the higher the number of inbound tourists to Australia. Likewise, the religion coefficient in both the baseline model and specification 3 is positive and significant at $1 \%$ level, suggesting 
Table 1

OLS Regressions

\begin{tabular}{|c|c|c|c|c|c|}
\hline & $\begin{array}{l}\text { Specification } 1 \\
\text { (Baseline) }\end{array}$ & Specification 2 & Specification 3 & Specification 4 & Specification 5 \\
\hline Language $(L)$ & $\begin{array}{l}2.457 * * * \\
(6.125)\end{array}$ & $\begin{array}{c}2.777 * * * \\
(7.026)\end{array}$ & & & \\
\hline Religion $(R)$ & $\begin{array}{l}3.185 * * * \\
(5.317)\end{array}$ & & $\begin{array}{c}4.598 * * * \\
(4.501)\end{array}$ & & \\
\hline Composite index $(L R)$ & & & & $\begin{array}{l}10.640 * * * \\
(8.262)\end{array}$ & $\begin{array}{l}10.547 * * * \\
(7.914)\end{array}$ \\
\hline Distance $(d)$ & $\begin{array}{c}-0.340 * * * \\
(-10.500)\end{array}$ & $\begin{array}{c}-0.286 * * * \\
(-9.623)\end{array}$ & $\begin{array}{c}-0.379 * * * \\
(-9.007)\end{array}$ & $\begin{array}{c}-0.298 * * * \\
(-9.590)\end{array}$ & $\begin{array}{c}-0.303 * * * \\
(-9.300)\end{array}$ \\
\hline Per capita real GDP $(\ln Y)$ & $\begin{array}{c}1.138 * * * \\
(7.715)\end{array}$ & $\begin{array}{l}0.931 * * * \\
(5.917)\end{array}$ & $\begin{array}{c}1.353 * * * \\
(7.391)\end{array}$ & $\begin{array}{c}0.985 * * * \\
(6.552)\end{array}$ & \\
\hline $\begin{array}{l}\text { Lagged per capita real } \\
\operatorname{GDP}\left(\ln Y_{-1}\right)\end{array}$ & & & & & $\begin{array}{l}0.991 * * * \\
(6.580)\end{array}$ \\
\hline Real exchange rate $(\ln E)$ & $\begin{array}{l}-0.058 \\
(1.484)\end{array}$ & $\begin{array}{l}-0.071 \\
(-1.538)\end{array}$ & $\begin{array}{c}-0.101 * * \\
(-2.247)\end{array}$ & $\begin{array}{l}-0.074 \\
(-1.647)\end{array}$ & $\begin{array}{l}-0.073 \\
(-1.614)\end{array}$ \\
\hline Population $(\ln P)$ & $\begin{array}{c}0.720 * * * \\
(11.697)\end{array}$ & $\begin{array}{c}0.649 * * * \\
(10.821)\end{array}$ & $\begin{array}{c}0.779 * * * \\
(8.863)\end{array}$ & $\begin{array}{c}0.657 * * * \\
(10.709)\end{array}$ & $\begin{array}{c}0.665 * * * \\
(10.865)\end{array}$ \\
\hline $\begin{array}{l}\text { Labor cost of alternative } \\
\text { destination country }(\ln W)\end{array}$ & $\begin{array}{l}0.016 \\
(1.077)\end{array}$ & $\begin{array}{c}0.022 \\
(1.523)\end{array}$ & $\begin{array}{c}0.014 \\
(0.948)\end{array}$ & $\begin{array}{l}0.022 \\
(1.494)\end{array}$ & $\begin{array}{c}0.022 \\
(1.491)\end{array}$ \\
\hline Intercept & $\begin{array}{l}-5.128 * * * \\
(-2.960)\end{array}$ & $\begin{array}{l}-2.382 \\
(-1.437)\end{array}$ & $\begin{array}{c}-7.368 * * * \\
(-3.165)\end{array}$ & $\begin{array}{l}-2.833 * \\
(-1.751)\end{array}$ & $\begin{array}{l}-2.895^{*} \\
(-1.814)\end{array}$ \\
\hline Adjusted $R^{2}$ & 0.797 & 0.740 & 0.650 & 0.773 & 0.771 \\
\hline$F$ statistics & 23.997 & 38.791 & 13.711 & 24.265 & 23.974 \\
\hline Wald test $p$-value & 0.000 & 0.000 & 0.000 & 0.000 & 0.000 \\
\hline Observation & 42 & 42 & 42 & 42 & 42 \\
\hline
\end{tabular}

Notes: Dependent variable is $\ln N$. Absolute $t$ statistics are in the parentheses. Robust standard errors are used.

$* * *, * *$, and $*$ denote significance levels at $1 \%, 5 \%$, and $10 \%$, respectively.

that religious similarity, like language similarity, is able to bring more tourists into a country. The composite cultural index in specification 4 is also significant at $1 \%$ level. All these results show that sharing similar culture can be a huge attraction in tourism. In addition, the cultural dissimilarity profile (i.e., with language dissimilarity index and religion dissimilarity index) is estimated to check for consistency. The results are found to be consistent with its counterpart; the dissimilarity results are not reported here but will be made available upon request.

Population coefficient is positive and significant at $1 \%$, indicating that highly populated countries generate higher volumes of tourists, ceteris paribus. This variable is often omitted in a tourism demand model but its role is highlighted in the gravity model. The inclusion of this variable could explain why China ranked fourth in the league table despite the huge difference in language and religion profile: 0.030 and 0.184 , respectively.

All control variables have expected signs. Per capita income, current and lagged, is both positive and significant at $1 \%$ level, suggesting that a higher income makes it more affordable for people to travel. The magnitude of the coefficient of the lagged income is no greater than the coefficient of current income reflecting a more time-compressed or accelerated world. No longer have people had to plan their travels way ahead. The real exchange rate coefficient is negative but not significant in most specifications; it is only significant at the $5 \%$ level in specification 3 . The negative sign indicates that a depreciation in the source country's currency reduces the number of tourist to the destination country by increasing the effective cost of travel. Yet, the nonsignificant coefficients are not entirely out of expectation. The rise of budget airlines has made transportation cost less intimidating (also reducing its percentage in the total outlay) to would-be travelers. As for the distance coefficient, it is negative and significant at the $1 \%$ level in all specifications, which confers the conventional wisdom that the closer the distance from the source country the more tourists arrivals to a destination country. 
As for the impact of the labor cost of alternative destination country, it is positive as expected but not significant in all model specifications. The result may suggest that the role of international price competition in the tourism industry is being overemphasized.

\section{Quantile Estimation Results}

The results of the baseline model with regression quantiles are presented in Table 2. OLS estimates provide a baseline for comparison with the estimates from the various quantiles of tourist arrivals into Australia. The estimation results at the conditional mean in specification 1 in Table 1 and the estimation results at the conditional median in specification 2 in Table 2 are similar except a drop in the religion coefficient from $1 \%$ to $5 \%$ significance. Both language and religion coefficients show some variation in magnitude across the three quantiles but are all highly significant in a statistical sense. This is an important result. It means that cultural similarity is equally important irrespective of the size of their contribution to Australia inbound tourism. As for the other explanatory variables, they are very consistent in their signs and significance levels over the different quantiles. From what we observed, we can conclude that the quantile regression results are consistent with that of the OLS results.

\section{Additional Tests}

Two tests are performed to check for coefficient restrictions and normality in the quantile regressions. The values of Wald statistics (for coefficient restrictions; see Table 2) show that the null hypothesisthat there is no shift in the conditional $\theta$ th quantile functions - cannot be rejected, which means that the culture impact is uniform across the various source countries. The satisfaction of the Jarque-Bera normality test shows that the normality assumption is valid. It is important to note that Newey-West estimator is used in all regressions to overcome the problem of heteroskedasticity and autocorrelation.

\section{Discussion and Concluding Remarks}

This article explored the measurement of cultural similarity between two countries by comparing their

Table 2

Quantile Regressions

\begin{tabular}{lccc}
\hline & Specification 1 & Specification 2 & Specification 3 \\
\hline Quantile $(\theta)$ & 0.25 & 0.5 & 0.75 \\
Language $(L)$ & $2.376^{* * *}$ & $2.796^{* * *}$ & $2.089^{* * *}$ \\
& $(3.849)$ & $(4.626)$ & $(3.287)$ \\
Religion $(R)$ & $2.890^{* *}$ & $2.670^{* *}$ & $3.960^{* * *}$ \\
& $(2.472)$ & $(2.047)$ & $(3.063)$ \\
Distance $(d)$ & $-0.320^{* * *}$ & $-0.315^{* * *}$ & $-0.314^{* * *}$ \\
& $(-6.491)$ & $(-6.358)$ & $(-6.600)$ \\
Per capita real GDP $(\ln Y)$ & $1.163^{* * *}$ & $1.1411^{* * *}$ & $1.178^{* * *}$ \\
& $(4.919)$ & $(5.362)$ & $(7.070)$ \\
Real exchange rate $(\ln E)$ & -0.036 & -0.004 & -0.052 \\
& $(-0.355)$ & $(0.050)$ & $(-1.129)$ \\
Population $(\ln P)$ & $0.708^{* * *}$ & $0.773 * * *$ & $\left(7.711^{* * *}\right.$ \\
& $(8.303)$ & $(8.722)$ & $(7.070)$ \\
Labor cost of alternative & 0.006 & 0.015 & 0.010 \\
destination country $(\ln W)$ & $(0.364)$ & $(0.992)$ & $(0.627)$ \\
Intercept & $-5.576^{*}$ & $-5.942^{* *}$ & $-5.665^{* *}$ \\
& $(-1.886)$ & $(-2.256)$ & $(-2.593)$ \\
Adjusted $R^{2}$ & 0.517 & 0.561 & 0.586 \\
$F$ statistics & 25.852 & 15.181 & 12.749 \\
Wald test $p$-value & 0.000 & 0.000 & 0.000 \\
Observation & 42 & 42 & 42 \\
\hline
\end{tabular}

Notes: Dependent variable is $\ln N$. Lower quantiles (e.g., $\theta=0.25$ ) signify least tourist country. Absolute $t$ statistics are in the parentheses. Robust standard errors are used.

$* * *, * *$, and $*$ denote significance levels at $1 \%, 5 \%$, and $10 \%$, respectively. 
profiles in both languages spoken and religions believed. A continuous, normalized, and time variant index, based on the Berry index was constructed for measuring language similarity. The index obtained can also withstand the test of ecological fallacy. A religion similarity index was constructed in the same vein. A composite index could be constructed by multiplying the two indexes together.

The two similarity indexes were incorporated into an empirical model, derived from the gravity model, to examine the nexus between tourism demand and cultural similarity. The inbound tourists from 42 source countries to Australia were regarded as export of services from Australia.

Both the OLS and quantile regression results were highly significant (mostly at the $1 \%$ level) and consistent over various specifications and quantiles. Our empirical results for the year 2010 reaffirmed the conventional wisdom about tourist income, traveling cost, and distance of the source countries on the number of inbound tourists to a destination country. It also highlighted the positive role played by cultural similarity between source and destination countries. The ability to communicate and the feeling of closeness to the people in the destination country would no doubt help tourism.

We found three significant observations. First, the regression results showed a strong nexus between cultural similarity and inbound tourism. Second, either language or religion similarity was a good proxy for cultural similarity. The composite index also worked out very well. Third, the effect of cultural similarity was consistent across the full spectrum of source countries, irrespective of the size of their contribution to inbound tourism of Australia.

For government policy makers and tourism operators alike, the empirical findings from this crosssectional study lend support to the belief that cultural similarity is important to tourism and that it should be fully exploited. The findings justify the continuous advertising campaigns carried out by Tourism Australia in the traditional Anglophone markets. That being said, advertising expenditure should also be spent on highly populated countries, such as China and India, which could generate a continuous inflow of tourists. Neighboring countries and highincome countries such as the Southeast Asian countries are also good sources of inbound tourists. These observations are largely supported by the inbound tourist numbers. The top three source countries in 2010 were countries with similar language and religion; they were New Zealand, the UK, and the US. Ranked fourth was China, the most populated country on earth and one of the top ranked source countries for migrants into Australia. The next five places were occupied by neighboring countries of Japan, Singapore, Malaysia, South Korea, and Hong Kong.

The findings in this study also lend support to multiculturalism. The intake of migrants from nonEnglish-speaking countries into Australia would undoubtedly help promote inbound tourism from those countries through not only visiting relatives but also other kinds of tourism. Multiculturalism is good for tourism and business in Australia. This may be drawing a long bow but it is probably not too far from the truth.

Last and not the least, we do acknowledge the weakness of measuring culture by using language and religion, a feature shared by other cross-cultural studies. Because the concept of culture is a construct, our approach could be seen as oversimplification. Until a new measure is put forward, it is the best we can do. Even though such crude measures are used, they yield very consistent and statistically significant regression results, and that is what matters.

\section{Notes}

${ }^{1}$ Hofstede (2001) added long-term orientation to his original four cultural scores.

${ }^{2} \mathrm{We}$ were indebted to an anonymous referee of alerting us to this condition.

${ }^{3}$ Ginsburgh (2005) found that people in the Eurosong Contest tend to vote for the countries that have the greatest resemblance to themselves.

${ }^{4}$ In calculating the Berry's index $(D)$, the $k$ activities of the diversified firm are in descending order. Then the Berry's index is defined as $D=1-\sum_{i=1}^{k} s_{i}^{2}$, where $s_{i}$ is the ratio of activity $i$ to the whole operation of the firm.

${ }^{5}$ After the completion of our manuscript, we discovered by chance that our similarity index was exactly the same developed Wagner, Head, and Fies (2002) and the dissimilarity index similar to that suggested by Boisso and Ferrantino (1997). This showed that some ideas could be developed independently.

${ }^{6}$ The 37 languages are Afrikaans, Arabic, Basque, Catalan, Chinese, Croatian, Danish, Dutch, English, Fijian, Filipino, Finnish, French, German, Greek, Hebrew, Hindi and other Indian languages, Irish, Italian, Japanese, Korean, Malay/ Indonesian, Melanesian/Polynesian, Norwegian, Persian and Dari, Polish, Portuguese, Russian, Serbian, Sinhalese, 
Spanish, Swedish, Tamil, Thai, Turkish, Vietnamese, others and unspecified.

${ }^{7}$ For those interested readers, the values of the language and religion similarity indexes for Australia are 0.624 and 0.248 , respectively.

${ }^{8}$ See "Table 5: Short-term Movement, Visitor ArrivalsSelected Countries of Residence: Original" of Australian Bureau of Statistics (2013).

${ }^{9}$ All Pacific island countries enter Australia via Brisbane. All East Asian countries and New Zealand, and
Americas enter Australia through Sydney. All European and subcontinent countries enter through Perth.

\section{Acknowledgment}

The authors would like to thank anonymous reviewers for their critical comments and suggestions.

Appendix

\begin{tabular}{|c|c|c|c|c|}
\hline Source Country & $\begin{array}{c}\text { Language } \\
\text { Similarity Index }\end{array}$ & $\begin{array}{c}\text { Religion } \\
\text { Similarity Index }\end{array}$ & $\begin{array}{c}\text { Distance } \\
\text { (in '000 km) }\end{array}$ & Alternative Destination \\
\hline Austria & 0.004 & 0.247 & 13.2410 & Italy \\
\hline Belgium & 0.006 & 0.294 & 14.1490 & France \\
\hline Brazil & 0.003 & 0.274 & 13.2720 & France \\
\hline Brunei & 0.023 & 0.060 & 5.7480 & Singapore \\
\hline Canada & 0.477 & 0.269 & 15.8520 & France \\
\hline China & 0.030 & 0.184 & 8.6630 & Hong Kong \\
\hline Denmark & 0.003 & 0.344 & 13.6810 & Germany \\
\hline Fiji & 0.010 & 0.226 & 2.7940 & New Zealand \\
\hline Finland & 0.002 & 0.324 & 13.0830 & Estonia \\
\hline France & 0.006 & 0.247 & 14.2660 & Italy \\
\hline Germany & 0.008 & 0.245 & 13.5630 & France \\
\hline Greece & 0.013 & 0.027 & 12.2770 & Bulgaria \\
\hline Hong Kong, China & 0.047 & 0.129 & 6.0230 & China \\
\hline India & 0.013 & 0.021 & 7.8670 & Saudi Arabia \\
\hline Indonesia & 0.003 & 0.047 & 3.0110 & Malaysia \\
\hline Ireland & 0.733 & 0.268 & 14.8790 & UK \\
\hline Israel & 0.139 & 0.019 & 11.1890 & USA \\
\hline Italy & 0.018 & 0.257 & 13.3270 & France \\
\hline Japan & 0.002 & 0.030 & 7.8210 & USA \\
\hline Korea & 0.003 & 0.186 & 8.3240 & China \\
\hline Malaysia & 0.023 & 0.053 & 4.1760 & Singapore \\
\hline Mexico & 0.010 & 0.253 & 13.3190 & USA \\
\hline New Zealand & 0.006 & 0.281 & 2.2240 & Fiji \\
\hline Netherlands & 0.716 & 0.250 & 14.1280 & France \\
\hline Norway & 0.006 & 0.327 & 13.8490 & Sweden \\
\hline Philippines & 0.019 & 0.320 & 6.0320 & China \\
\hline Papua New Guinea & 0.007 & 0.266 & 2.0950 & Solomon Island \\
\hline Poland & 0.007 & 0.257 & 13.0580 & Ukraine \\
\hline Russia & 0.018 & 0.133 & 12.2070 & Ukraine \\
\hline S Africa & 0.189 & 0.097 & 8.0230 & Zimbabwe \\
\hline Singapore & 0.127 & 0.308 & 3.9010 & Malaysia \\
\hline Spain & 0.011 & 0.264 & 14.6000 & France \\
\hline Sri Lanka & 0.008 & 0.049 & 5.7600 & India \\
\hline Sweden & 0.006 & 0.322 & 13.4340 & Denmark \\
\hline Switzerland & 0.015 & 0.268 & 13.8540 & France \\
\hline Taiwan & 0.026 & 0.038 & 7.2590 & China \\
\hline Thailand & 0.013 & 0.023 & 5.3320 & Malaysia \\
\hline United Arab Emirates & 0.698 & 0.280 & 9.0420 & Saudi Arabia \\
\hline United Kingdom & 0.067 & 0.024 & 14.4640 & Spain \\
\hline United States & 0.651 & 0.256 & 15.6000 & Mexico \\
\hline Vanuatu & 0.198 & 0.295 & 1.9050 & New Zealand \\
\hline Vietnam & 0.020 & 0.173 & 5.9800 & Cambodia \\
\hline
\end{tabular}




\section{References}

Akerlof, G. A., \& Kranton, R. E. (2000). Economics and identity. Quarterly Journal of Economics, 115(3), 715-753.

Anderson, J. E. (1979). A theoretical foundation for the gravity equation. American Economic Review, 69(1), $106-116$

Anderson, J. E., \& van Wincoop, E. (2003). Gravity with gravitas: A solution to the border puzzle. American Economic Review, 93(1), 170-192.

Australian Bureau of Statistics. (2007). 2006 Census community profile series (Cat. No. 2001.0). Canberra: Commonwealth of Australia.

Australian Bureau of Statistics. (2013). Overseas arrivals and departures, Australia (Cat. No. 3410.0). Canberra: Commonwealth of Australia.

Beckerman, W. (1956). Distance and the pattern of intraEuropean trade, Review of Economics and Statistics, 38(1), 31-40.

Bergstrand, J. A. (1985). The gravity equation in international trade: Some microeconomic foundations and empirical evidence. Review of Economics and Statistics, 67(3), 474-481.

Boisso, D., \& Ferrantino, M. (1997). Economic distance, cultural distance, and openness in international trade: Empirical puzzles, Journal of Economic Integration. 12(4), 456-484.

Boukas, N., Ziakas, V., \& Boutstras, G. (2013). Olympic legacy and cultural tourism: Exploring the facets of Athens' Olympic heritage. International Journal of Heritage Studies, 19(2), 203-228.

Cavalli-Sforza, L. L., Menozzi, P., \& Piazza, A. (1994). The history and geography of human genes. Princeton, NJ: Princeton University Press.

Central Intelligence Agency. (2012). The CIA world factbook 2013. New York: Skyhorse Publishing.

Chen, M. K. (2013). The effect of language on economic behavior: Evidence from savings rates, health behaviors, and retirement assets. American Economic Review, 103(2), 690-731.

Crotts, J. C. (2004). The effect of cultural distance on overseas travel behaviors. Journal of Travel Research, 43, $83-88$.

Crouch, G. I., \& Ritchie, J. R. B. (1999). Tourism, competitiveness, and social prosperity. Journal of Business, 44, $137-152$

Eff, E. A. (2004). Spatial and cultural autocorrelation in international datasets. Working paper, Department of Economics and Finance, Middle Tennessee University.

Eff, E. A. (2008). Weight matrices for cultural proximity: Deriving weights from a language phylogeny. Structure and Dynamics, 3(2), 1-15.

European Commission. (2012). Special Eurobarometer 386: Europeans and their languages, Retrieved November 26, 2012, from http://ec.europa.eu/public_opinion/archives/ ebs/ebs_386_en.pdf

Felbermayr, G. J., \& Toubal, F. (2010). Cultural proximity and trade. European Economic Review, 54(2), 279-93.
Galí-Espelt, N. (2012). Identifying cultural tourism: A theoretical methodological proposal. Journal of Heritage Tourism, 7(1), 279-293.

Ginsburgh V. (2005). Languages, genes, and cultures, Journal of Cultural Economics, 29, 1-17.

Guiso, L., Sapienza, P., \& Zingales, L. (2006). Does culture affect economic outcomes? Journal of Economic Literature, 20(2), 23-48.

Guo, R. (2007). Linguistic and religious influences on foreign trade: Evidence from East Asia. Asian Economic Journal, 21(1), 101-121.

Henderson, D. J., \& Millimet, D. L. (2008). Is gravity linear? Journal of Applied Econometrics, 23, 137-172.

Hofstede, G. (1980). Culture's consequences: International differences in work-related values. Beverly Hills, CA: Sage Publications.

Hofstede, G. (2001). Culture's consequences: Comparing values, behaviors, institutions, and organizations across nations (2nd ed.). Thousand Oaks, CA: Sage Publications.

Hutchinson, W. K. (2005). "Linguistic distance" as a determinant of bilateral trade. Southern Economic Journal, 72(1), 1-15.

Isphording, I. E., \& Otten, S. (2013). The costs of Babylon-Linguistic distance in applied economics. Review of International Economics, 21(2), 354-369.

Johanson, J., \& Vahlne, J. E. (1977). The internationalization process of a firm: A model of knowledge development and increasing foreign market commitment. Journal of International Business Studies, 8, 22-32.

Karemera, D., Oguledo, V. I., \& Davies, B. (2000). A gravity model analysis of international migration to North America. Applied Economics, 32(13), 1745-1755.

Lazear, E.P. (1999). Cultural and language. Journal of Political Economy, 107(S6), S95-S126.

Lim, C. (2006). A survey of tourism demand modeling practice: Issues and implications. In L. Dwyer \& P. Forsyth (Eds.), International handbook on the economics of tourism (pp. 45-72). Northampton, UK: Edward Elgar Publishing.

McKercher, B., \& du Cros, H. (2003). Testing a cultural tourism typology. International Journal of Tourism Research, 5, 45-58.

$\mathrm{Ng}$, S. I., Lee, J. A., \& Soutar, G. N. (2006). Tourists' intention to visit a country: The impact of cultural distance. Tourism Management, 28, 1497-1506.

Rauch, J. E., \& Trindade, V. (2002). Ethnic Chinese networks in international trade. Review of Economics and Statistics, 84(1), 116-130.

Richards, G. (1996) Production and consumption of European cultural tourism. Annals of Tourism Research, 23(2), 261-283.

Saha, S., Gounder, R., \& Su, J. J. (2009). The interaction effect of economic freedom and democracy on corruption: A panel cross-country analysis, Economics Letters, 105, 173-176.

Saha, S., \& Yap, G. (2014). The moderation effects of political instability and terrorism on tourism development: A 
cross-country panel analysis. Journal of Travel Research, 53(4), 509-521.

Shen, C., \& Williamson, J. B. (2005). Corruption, democracy, economic freedom, and state strength: A crossnational analysis. International Journal of Comparative Sociology, 46(4), 327-345.

Seetanah, B., Durbarry, R., \& Ragodoo, J. F. N. (2010). Using the panel cointegration approach to analyse the determinants of tourism demand in South Africa. Tourism Economics, 16(3), 715-729.
Vietze, C. (2012). Cultural effects on inbound tourism into the USA: A gravity model. Tourism Economics, 18(1), 121-138.

Wagner, D., Head, K., \& Ries, J. (2002). Immigration and the trade of provinces. Scottish Journal of Political Economy, 49(5), 507-525.

Zhang, J., \& Jensen, C. (2007). Comparative advantage: Explaining tourism flows. Annals of Tourism Research, 34(1), 223-243. 
